\title{
A IMPORTÂNCIA DO CAPITAL SOCIAL NA ABERTURA DE EMPRESA
}

\author{
Elia Denise Hammes ${ }^{1}$ \\ Lígia Margarete Mallmann
}

\section{RESUMO}

O objetivo deste artigo é realizar uma contextualização sobre a importância do capital social na abertura de uma empresa, apontando as implicações jurídicas e de gestão. Por meio do método dialético e da pesquisa descritiva concluir-se-á, que o capital social no ato constitutivo não é mera formalidade, da indicação do valor decorrem consequenciais jurídicas, direito de credores, responsabilidades assumidas pelo titular individual e dos sócios, possibilidade de expulsão do sócio remisso na sociedade limitada, credibilidade junto a investidores, garantia de capital de giro, além da gestão da empresa.

Palavras-chave: Capital social. Empresas. Gestão. Segurança jurídica. Integralização.

\section{THE IMPORTANCE OF SOCIAL CAPITAL IN OPENING A COMPANY}

\begin{abstract}
The objective of this article is to provide a contextualization about the importance of social capital in the opening of a company, pointing out the legal and management implications. Through the dialectical method and descriptive research, it will be concluded that the capital in the constitutive act is not a mere formality, the indication of the value derives from legal consequences, creditors' rights, responsibilities assumed by the individual holder and the partners, possibility of expulsion of the remission partner in the limited liability company, credibility with investors, guarantee of working capital, in addition to the company's management.
\end{abstract}

Keywords: Social capital. Companies. Management. Legal certainty. Payment.

\section{Introdução}

O capital social pode ser analisado sob diferentes perspectivas, como por exemplo a perspectiva contábil, sociológica e também a perspectiva jurídica Trata-se de cláusula obrigatória nos atos constitutivos das empresas, sejam elas individuais ou societárias.

\footnotetext{
*Doutora em Desenvolvimento Regional e Mestre em Direito, Advogada OAB/RS no 43.345 - Professora de Direito Empresarial do Curso de Direito da Universidade de Santa Cruz do Sul - UNISC. Consultora junto aos empreendimentos incubados na Incubadora Tecnologica- ITUNISC da mesma Universidade. e-mail: elia@unisc.br

* Doutora e Mestre em Desenvolvimento Regional, Administradora CRA/RS n 22.705- Professora de Finanças do Curso de Administração da Universidade de Santa Cruz do Sul - UNISC. Consultora junto aos empreendimentos incubados na Incubadora Tecnologica- ITUNISC da mesma Universidade. e-mail: ligiamallmann@unisc.br
} 
Enquanto na parte contábil o capital social é o valor dos bens ou do recurso financeiro com que os sócios contribuem para a constituição de uma empresa sem direito de devolução, para a sociologia, o capital social é o que possibilita a cooperação entre duas partes. A noção não implica necessariamente algo positivo, já que os contatos entre as pessoas podem dar lugar a situações negativas (como as sociedades mafiosas, por exemplo). No lastro da sociologia Pierre Bourdieu definiu o conceito de capital social como "o agregado dos recursos efetivos ou potenciais ligados à posse de uma rede durável de relações mais ou menos institucionalizadas de conhecimento ou reconhecimento mútuo" (BOURDIEU, 1980, p. 248).

De acordo com Bourdieu (2002), o capital social se inter-relaciona com capital cultural e econômico, por meio de trocas gerando reconhecimento para os indivíduos no grupo ao qual se insere. A quantidade de capital social que um indivíduo tem depende, portanto, da extensão de relações que ele consegue mobilizar e do volume de capital econômico, cultural e simbólico que é de propriedade única de cada elemento do grupo. Nessa esteira, para Putnam (1993, p. 1) "capital social refere-se a aspectos da organização social, tais como redes, normas e confiança que facilita coordenação e cooperação para benefícios mútuos. Capital social aumenta os benefícios de investimento em capital físico e capital humano".

Para determinar o capital social diante dos outros tipos de capital, é imprescindível compreender o termo "capital". A finalidade aqui não é revisar toda a evolução e os debates sobre o conceito, mas somente precisar a utilização que é feita dele no segmento empresarial. O capital social é utilizado aqui para designar bens, recursos ou equipamentos que são (ou podem ser) investidos na abertura de uma empresa.

O objetivo deste artigo é realizar uma contextualização sobre a importância do capital social na abertura de uma empresa, apontando implicações jurídicas e de gestão que se evidenciam com o tema, especificadamente nos tipos empresariais individuais e na sociedade limitada. Por meio do método dialético, e da pesquisa descritiva contextualizando, as autoras que atuam junto a consultorias de empresas nascentes em Incubadora tecnológica de Universidade, objetivam enfrentar questões que se mostram com grande dificuldade com o manuseio do tema entre os empreendedores, por entenderem, na grande maioria das vezes, que a indicação do capital social no ato constitutivo é mera formalidade.

Desta forma, primeiramente descreve-se sobre o capital social para a constituição de uma empresa, na sequencia mostra-se a importância do planejamento do empreendedorismo, sendo o capital social parte desse planejamento para o sucesso do negócio. Após abordaremos 
os tipos empresariais, destacando os tipos empresariais individuais e a sociedade limitada e a exigência de capital social mínimo. Na sequência a abordagem será relacionada a diferenciação do patrimônio social e a integralização do capital social, temas que devem ser discutidos e esclarecidos na expectativa da abertura de uma empresa, bem como, as consequências jurídicas na falta de integralização do capital social.

\section{Capital social para a constituição de uma empresa}

Para a constituição de qualquer atividade empresarial é necessário um aporte de recursos (dinheiro e/ou bens), ou seja, o capital social. Os recursos devem ser definidos antes da constituição da empresa e é um valor que os sócios investem sem uma garantia de retorno, podendo gerar insegurança. Esse valor pode ser alterado posteriormente, para mais ou para menos, mediante aprovação dos sócios e alteração do Contrato Social, ou decisão do único titular da atividade empresária. Não existe nenhuma fórmula ou padrão para a definição do capital social para a abertura de uma empresa. Ele vai depender das necessidades levantadas pelos sócios, a compra de equipamentos e a contratação de serviços iniciais entre outros.

Conforme Santos (2010), os recursos financeiros são considerados de fundamental relevância no processo de abertura de um empreendimento. No entanto, uma das grandes características das empresas nascentes é a dificuldade de acessar capital financeiro, principalmente de procedência formal, como investidores e empréstimos, já que geralmente estas empresas não possuem histórico das suas atividades. Neste sentido, Dornelas (2008) explicita a importância da elaboração de um plano de negócios bem estruturado para planejar as ações e delinear as estratégias da empresa a ser criada. O plano de negócios é uma ferramenta de múltiplas aplicações. Mas, para empresas nascentes é um instrumento de forte notoriedade para a captação de recursos financeiros junto a capitalistas de risco.

O capital social constitui o fundo originário, o núcleo inicial do patrimônio da pessoa jurídica, do qual será viabilizado o início da vida econômica da sociedade empresarial (tudo o que é de sua propriedade). Para saber o valor suficiente de recursos e formar o capital social de uma empresa nascente, é necessário elaborar uma projeção minuciosa de todas as despesas, equipamentos, encargos, impostos entre outros. Além disso, é de fundamental importância realizar uma pesquisa mercadológica, para validar o produto e/ou serviço no mercado. Desta forma, torna-se possível estimar a projeção das receitas. 
O capital social de uma empresa nascente deve estimar um aporte de recursos, para sustentar o financiamento de suas operações. Ou seja, deve cobrir as contas que precisam ser honradas para manter suas atividades. Esta projeção tem que considerar o prazo até que a empresa consiga ter resultados financeiros, para começar a pagar seus compromissos com recursos oriundos de suas receitas, este recurso é conhecido como capital de giro. Na contabilidade, essa visão de equilíbrio ocorre na comparação entre as chamadas contas do ativo e passivo circulante (GITMAN, 2010). De acordo com a Lei $\mathrm{n}^{\circ} 11.638 / 07$, MP $\mathrm{n}^{\circ}$

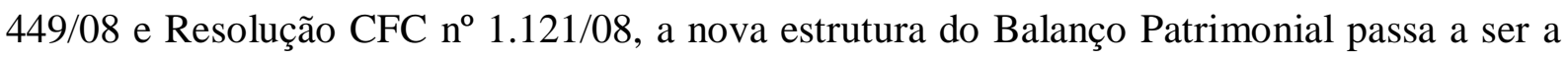
seguinte:

Quadro 1: Exemplo de Balanço Patrimonial

\begin{tabular}{|c|c|}
\hline \multicolumn{2}{|c|}{ BALANÇO PATRIMONIAL } \\
\hline ATIVO & PASSIVO \\
\hline Circulante & Circulante \\
\hline Disponibilidade & Fornecedores \\
\hline Créditos & Obrigações trabalhistas \\
\hline Estoques & Empréstimos e financiamentos (curto prazo) \\
\hline \multirow[t]{3}{*}{ Outros créditos } & Obrigações tributárias \\
\hline & Provisões e encargos das provisões \\
\hline & Outras obrigações \\
\hline Não circulante & Não circulante \\
\hline Realizável a longo prazo & Exigível a longo prazo \\
\hline \multicolumn{2}{|l|}{ Investimentos } \\
\hline Imobilizado & Patrimônio Líquido \\
\hline Intangível & Capital social \\
\hline \multirow[t]{3}{*}{ Depreciação acumulada (-) } & Lucro/Prejuízos acumulados \\
\hline & Reserva de capital \\
\hline & Ajustes de avaliação patrimonial \\
\hline TOTAL DO ATIVO & TOTAL DO PASSIVO \\
\hline
\end{tabular}

Fonte: Elaborado pelas autoras com base em Gitman, 2010

Neste sentido, Assaf Neto (2010) reforça que a administração financeira de curto prazo é assim chamada porque se relaciona com a gestão do capital de giro. As operações mais comuns nessa área de finanças se referem aos investimentos em créditos a clientes, ao gerenciamento do caixa e à estrutura dos passivos correntes (obrigações). Além disso, Gitman (2010) destaca que é papel do gestor é buscar o equilíbrio entre rentabilidade e risco, avaliando as contas do ativo e passivo circulantes com operações de curto prazo. Entende-se aqui como curto prazo as operações que ocorrem em um ano ou menos. Período muito delicado para uma empresa nascente, que não elaborou um Plano de Negócio. 
Caciatori Jr e Iarozinski Neto (2006) destacam que as maiores causas de fechamento de empresas, especialmente as empresas nascentes, referem-se à falta de uma tomada de decisão assertiva na gestão financeira de curto prazo, principalmente quanto ao capital de giro. De acordo com Sebrae (2020) não é possível atribuir a um único fator a causa da mortalidade, mas sim, a uma combinação de fatores em quatro grandes áreas: a situação do gestor (empresário) antes da abertura, o planejamento dos negócios, a capacitação em gestão empresarial e a gestão do negócio em si. Desta forma, chama-se a atenção para a relevância do planejamento, antes da abertura da empresa.

Considerando tal contexto, é importante observar alguns critérios para definir o valor do capital social, antes da abertura da empresa. O capital social estabelece também as regras entre os indivíduos que compõem a sociedade, levando em consideração os objetivos da empresa e a forma como ela será organizada. Assim, ele determina o poder de cada sócio e a limitação de sua responsabilidade, conforme a quantia de recursos, que cada membro da sociedade investiu. Assim, Dornelas (2008), explicita que quando uma pessoa detecta uma oportunidade e cria um negócio para capitalizar sobre ela, está assumindo riscos calculados. Esta decisão torna-o empreendedor, o qual precisa estabelecer normas e cumprir regras contratuais.

\section{Empreendedorismo e o capital social}

De acordo com Dornelas (2008), o empreendedorismo é o envolvimento de pessoas e processos que, em conjunto, levam a transformar de ideias em oportunidades. É a implementação destas oportunidades que levam à criação de negócios de sucesso. Para o termo "empreendedor" existem muitas definições, mas uma das mais antigas e que talvez melhor reflita o espírito empreendedor seja a de Josepf Schumpeter (1949), citada por Dornelas $(2008$, p. 22) “o empreendedor é aquele que destrói a ordem econômica existente pela introdução de novos produtos e serviços, pela criação de novas formas de organização ou pela exploração de novos recursos e materiais.” Não há unanimidade entre os autores quanto aos tipos de empreendedores.

Pessoa (2005) citado por Baggio e Baggio (2014) define em três os principais tipos de empreendedores: $\mathrm{O}$ empreendedor corporativo (intra-empreendedor ou empreendedor interno), o empreendedor startup (que cria novos negócios/empresas) e o empreendedor social 
(que cria empreendimentos com missão social). O empreendedorismo corporativo pode ser definido como sendo um processo de identificação, desenvolvimento, captura e implementação de novas oportunidades de negócios, dentro de uma empresa existente.

O empreendedor startup tem como objetivo dar origem a um novo negócio. Ele analisa o cenário e diante de uma oportunidade apresenta um novo empreendimento. Busca e apresenta diferenciais competitivos em um mercado já existente; vencer a concorrência; conquistar clientes; e alcança a lucratividade e a produtividade necessárias à manutenção do empreendimento. Já o empreendedorismo social é um misto de ciência e arte, racionalidade e intuição, ideia e visão, sensibilidade social e pragmatismo responsável. O empreendedorismo social difere do empreendedorismo propriamente dito em dois aspectos: não produz bens e serviços para vender, mas para solucionar problemas sociais, e não é direcionado para mercados, mas para segmentos populacionais em situações de risco social.

Conforme Dornelas (2008), as características dos empreendedores de sucesso são: visionários; sabem tomar decisões; são indivíduos que fazem a diferença; sabem explorar ao máximo as oportunidades; são determinados e dinâmicos; otimistas e apaixonados pelo que fazem; independentes e constroem o próprio destino; líderes e formadores de equipes; são bem relacionados (networking); organizados e planejam. Mas, precisam cumprir alguns procedimentos para transformar a ideia em negócio competitivo.

Desta forma, para a abertura de uma empresa é necessário realizar uma previsão financeira orçamentária, com recursos financeiros próprios ou de terceiros, ou seja, buscar um sócio ou contratar um financiamento. Muitas vezes o veículo que permite ao empreendedor encontrar sócios ou parceiros é sua rede de relação, principalmente os contatos fortes (família, amigos e ex-colegas de trabalho $)^{2}$, (BORGES, 2011).

De acordo com o Sebrae (2020), o valor total do capital social da empresa deve ser estabelecido conforme o plano de negócios desenvolvido previamente, após estudos aprofundados sobre o setor de atuação. É importante realizar uma previsão financeira orçamentária, dos custos operacionais, estimativa de capital de giro necessário para segurar a empresa (mesmo que ela não dê nenhum lucro nos primeiros meses), despesas com folha de

\footnotetext{
${ }^{2}$ Para Dornelas (2008), um fator muito importante é a formação da sociedade, se os membros possuem formação eclética, como é o perfil de cada membro, quais habilidades e competências que cada um possui. Mas, de nada adianta ter uma equipe com todas as características empreendedoras, se as pessoas estiverem no negócio apenas atrás das compensações financeiras, sem paixão e orgulho pelo que pretendem desenvolver, sem comprometimento. Neste caso, o envolvimento poderá ser superficial e não haverá muita preocupação com a utilização dos recursos disponíveis.
} 
pagamento, visão institucional, entre outras variáveis. Juridicamente o capital social possui várias funções e papeis em relação a empresa, sócios e terceiros.

\section{Tipos empresariais e a imposição legal de capital social mínimo}

Todos os tipos empresariais devem especificar seu capital social, tanto a figura do Empresário Individual, a Empresa Individual de Responsabilidade Limitada, o Microempreendedor Individual-MEI e as sociedades. Em relação as sociedades trataremos em especifico da sociedade limitada, que representa em todo o Brasil o maior número de sociedades existentes, conforme dados do mapa de empresas de 2020 (https://www.gov.br/governodigital/pt-br/mapa-de-empresas/boletins/mapa-de-empresasboletim-do-3o-quadrimestre-de-2020.pdf).

Atualmente a legislação brasileira autoriza o empreendedor a se formalizar por meio da escolha de um dos tipos empresariais previstos na legislação pátria, sendo a figura jurídica do Microempreendedor Individual, Empresário Individual, Empresa Individual de Responsabilidade Limitada e os diferentes tipos societários, destacando-se a sociedade limitada e a sociedade anônima.

A Figura jurídica do Microempreendedor Individual- MEI é uma política pública existente desde 2008, introduzida na legislação brasileira por meio da Lei Complementar $n^{\circ}$ 128 de 2008. Essa política pública teve como principal objetivo retirar inúmeros trabalhadores e empreendedores da informalidade. Não há exigência de um capital social mínimo para iniciar a atividade, no entanto, apresenta alguns limitadores, como por exemplo, em relação ao faturamento no período anual, que atualmente, não pode ser superior a $\mathrm{R} \$$ $81.000,00$ (oitenta e um mil reais). Além disso, pode ter apenas um empregado contratado e nem todas as atividades podem ser MEI, devendo ser observado a lista de atividades aprovada pelo Comitê Gestor do Simples Nacional-CGSN.

De outro lado, o MEI contribui para a previdência social e paga todos os tributos com um valor mensal muito abaixo dos demais tipos empresariais, por meio de uma única guia. Nesse formato, o empreendedor se formaliza e recebe um Cadastro Nacional de Pessoa Jurídica -CNPJ da Receita Federal, no entanto, para fins legais não constitui pessoa jurídica.

A figura do Empresário Individual- EI, do mesmo modo que o MEI não constitui pessoa jurídica para fins legais, embora também receba um CNPJ da Receita Federal para operar sua 
atividade empresária. Nesse formato também não há capital social mínimo a ser estabelecido, senão aquele necessário para iniciar a atividade empresária.

Nessa modalidade também não há limite de faturamento e todas as atividades, desde que lícitas, podem ser exploradas pelo empresário, com o número de colaborares que for necessário para desenvolver a atividade.

Os dois tipos empresariais anteriormente mencionados não constituem pessoa jurídica para fins legais, conforme pode ser observado no art 44 do Código Civil que lista as pessoas jurídicas de direito privado no Brasil. ${ }^{3}$.

O Estado brasileiro, considerando seu papel de defesa da ordem econômica, poderá determinar a estipulação, por força de lei, um valor mínimo de capital social, buscando garantir a estabilidade do negócio bem como a garantia mínima dos credores do empresário, seja individual ou societário, como ocorre, por exemplo, com a EIRELI.

A Empresa Individual de Responsabilidade Limitada-EIRELI, criada pela $\mathrm{n}^{\circ}$ 12.441/2011, com vigência a partir de janeiro de 2012, se diferencia dos tipos empresarias anteriores, visto que além de constituir pessoa jurídica, conforme art 44 do Código Civil, também lhe é imposto a exigência de haver um capital social mínimo exigido pelo Estado para fins de exploração da atividade econômica empresaria que, de acordo com o Art. 980-A do Código Civil, é de cem salários mínimos integralizados no ato da sua constituição.

A sociedade Limitada representa a grande maioria das sociedades constituídas no Brasil, de acordo com o mapa de empresas no Brasil publicado no site https://www.gov.br/governodigital/pt-br/mapa-de-empresas/ (acessado em 14 de outubro de 2020). A sociedade limitada, a partir Lei $n^{\circ} 13.874 / 2019$, que também é chamada de lei da liberdade econômica, pode ser tanto pluripessoal quanto unipessoal. Ambas as modalidades de sociedade limitada constituem pessoa jurídica e não possuem exigência estatal de um capital social mínimo para iniciar as atividades, mitigando cada vez mais a figura da EIRELI.

Aos tipos empresariais que constituem pessoa jurídica, por força de Lei, geram uma autonomia patrimonial em relação ao titular da EIRELI e aos sócios da sociedade Limitada, ou seja, o patrimônio pessoal não se confunde com o patrimônio da pessoa jurídica. E a fim de

\footnotetext{
${ }^{3}$ Por tal razão, o Tribunal de Justiça de Santa Catarina, em decisão transcrita na obra de Requião (2014, p. 114) inclusive já se manifestou que "o empresário individual [...] é a própria pessoa física ou natural, respondendo os seus bens pelas obrigações que assumiu, quer sejam civis, quer comerciais. A transformação de firma individual em pessoa jurídica é uma ficção do direito tributário, somente para efeitos de imposto de renda" Trecho extraído da Apelação Cível n $8.447-L a j e s$, in Bol. Jur. ADCOAS, n 18.878/73.
} 
reafirmar tal questão, recentemente, foi introduzido o Art 49-A do Código Civil com o seguinte teor:

Art. 49-A. A pessoa jurídica não se confunde com os seus sócios, associados, instituidores ou administradores.

Parágrafo único. A autonomia patrimonial das pessoas jurídicas é um instrumento lícito de alocação e segregação de riscos, estabelecido pela lei com a finalidade de estimular empreendimentos, para a geração de empregos, tributo, renda e inovação em benefício de todos.

Nesse sentido, é possível perceber que há uma maior segurança jurídica para o empreendedor, que poderá destacar parte de seu patrimônio para desenvolver a atividade empresária, que sempre carrega os riscos inerentes ao próprio negócio, deixando a outra parte do patrimônio na seara do patrimônio pessoal, e que, em regra, não pode ser utilizado para pagamento dos débitos da pessoa jurídica constituída para a exploração da atividade empresária ${ }^{4}$.

Nesse mesmo sentido, Bertoldi e Ribeiro (2015, p. 257), referindo-se as sociedades afirmam que, para que as sociedades "possam cumprir seu objetivo econômico, deverá contar com a capacidade financeira advinda dos recursos que são transferidos do patrimônio de seus sócios para o seu próprio acervo", gerando a chamada autonomia patrimonial. A constituição de pessoa jurídica também gera legitimidade processual da pessoa jurídica - que poderá ser autora ou réu em ações judiciais, bem como a titularidade obrigacional que significa que a pessoa jurídica pode contrair obrigações em seu próprio nome, como por exemplo, financiamento junto a instituições financeiras, contrato com fornecedores, contrato com investidores, entre outras obrigações ${ }^{5}$.

Portanto, conforme já mencionamos, quanto ao capital social, apenas a EIRELI possui, por força de lei, um capital social mínimo para ser constituída, nos demais casos não há imposição legal quanto ao mínimo a título de capital social ${ }^{6}$. Assim, é necessário que haja capital social a ser subscrito pelo titular individual ou pelos sócios.

De acordo com Chagas (2019, p. 247) “o capital social traduz-se na soma dos valores dos bens ou em dinheiro que os sócios aplicam, no momento da constituição ou por virtude de

\footnotetext{
${ }^{4}$ Salvo exceções previstas em Lei como é o caso do instituto da desconsideração da personalidade jurídica, nos termos do Art. 50 do CC.

5 Conforme dispõe o Art. 1.022 do CC: A sociedade adquire direitos, assume obrigações e procede judicialmente, por meio de administradores com poderes especiais, ou, não os havendo, por intermédio de qualquer administrador.

6 Há atividades empresariais especificas que legislação especial determina capital social mínimo, independentemente do tipo empresarial, a fim de assegurar direito dos consumidores, como exploração econômica de consórcio, seguros de vida, instituições financeiras, entre outras.
} 
deliberação posteriores, para formar o patrimônio da sociedade" E segue afirmando ainda que “esses valores serão o aporte de recursos com o qual será possível à sociedade atingir o fim a que se destina." (CHAGAS, 2019, p. 247)

De acordo com Mamede (2013, p. 80) “a constituição da empresa demanda a destinação de valores, em montante suficiente e especifico para o cumprimento de seu objeto e de sua finalidade (lucro)", que conforme já observado, pode ser apurado por meio do plano de negócios que permite um planejamento equilibrado do negócio.

Importante destacar que de acordo com Mamede (2013) esse investimento inicial é o capital que o empresário deverá declarar, quando de sua inscrição junto ao registro de empresas mercantis a cargo das juntas comerciais de cada Estado, necessário a ser investido em sua empresa [...] podendo realiza-lo em dinheiro, créditos e/ou bens.

Nesse sentido, considerando o aporte legal dos tipos empresariais admitidos no direito brasileiro, a EIRELI exige, por imposição estatal, um valor mínimo, de cem salários mínimos, de capital social. Já os demais tipos empresariais individuais e a sociedade Limitada não estão obrigados, por dispositivo legal, de ter um capital social mínimo. No entanto, fundamental que haja um prévio planejamento do empreendedor, por meio do plano de negócio, a fim de fixar e efetivamente integralizar um valor de capital social para fins de arcar com as despesas previamente mapeadas no plano de negócios, mesmo que não seja apurados lucros nos primeiros exercícios financeiros. Dito de outra maneira, o capital social não poder ser ficto e mesmo que não havendo imposição do Estado de capital social mínimo para a maioria dos tipos empresariais, esse precisa ser fixado e condizer à realidade àquela empresa.

\section{O patrimônio social e a integralização do capital social}

Importante ainda destacar que o capital social e o patrimônio em nome de uma empresa individual ou societária não se confundem. Ambos os valores provavelmente terão a mesma cifra apenas no primeiro dia de operação da atividade econômica, visto que a partir daí o capital social vai se manter intangível, salvo alteração do ato constitutivo, e o patrimônio se desenvolverá conforme a atuação da empresa.

Nesse sentido, Chagas (2019, p. 247) aponta que “ o patrimônio da sociedade não se confunde com o seu capital social. Este último consubstancia a expressão numérica, em 
moeda, do valor do patrimônio que ingressou na sociedade por força da contribuição dos sócios", ou do empreendedor individual.

Nesse mesmo sentido Bertoldi e Ribeiro (2015, p.257), quando afirmam que:

Não há que se confundir capital social com patrimônio da sociedade: enquanto este sofre constantes mudanças no decorrer da vida da sociedade, dependendo dos seus resultados positivos ou negativos, o capital social, a princípio matem-se inalterado, a menos que se delibere por seu aumento ou diminuição.

Ainda de acordo com Chagas (2019, p. 247), o patrimônio abrange o conjunto de direitos e de bens, corpóreos e incorpóreos, e oscila, cresce e diminui, à medida das exigências do mercado ou com expansão ou o encolhimento das atividades sociais. "O capital, de sua parte, é um valor permanente, que corresponde à massa patrimonial que os sócios (ou titular individual) entenderam suficiente" para a empresa atuar.

O patrimônio empresarial será levantado no balanço, que deve ser anual, na maioria das empresas, ou como menciona Mamede (2013) o patrimônio "é o conjunto das relações jurídicas positivas (ativo) e negativas (passivo). A evolução do patrimônio empresarial dependerá da gestão e das decisões dos sócios, administradores ou do titular da empresa", além e outras variáveis que podem interferir no seu desenvolvimento, como por exemplo o próprio mercado. Nessa lógica, enquanto, "normalmente, patrimônio e capital social se equivalem no momento da constrição, a tendência é a de que, no decorrer da vida social, eles se distanciem." (CHAGAS, 2019, p. 248)

Ainda sobre o patrimônio empresarial, é comum encontrar confusão entre o patrimônio pessoal dos sócios ou do titular da empresa individual e o patrimônio empresarial. Porém, tais patrimônios também, devem ser individualizados, ou seja, o patrimônio empresarial é aquele que compõe o patrimônio da pessoa jurídica ou nos casos de o tipo empresarial não constituir pessoa jurídica, como é o caso do MEI e do EI, aquele que é usado para a exploração da atividade econômica empresária. Já o patrimônio pessoal é aquele que pode ser conjugal ou estar registrado no Cadastro de Pessoa Física - CPF e de uso pessoal. Tais patrimônios também não se confundem com o lucro que é o resultado apurado e distribuído, quando positivo, aos sócios ou ao titular da empresa individual.

\section{A integralização do capital social}


Conforme já mencionado, o capital social deve ser integralizado pelos sócios ou titular da empresa individual, por meio de bens, dinheiro ou ainda por meio de endosso de título de credito. Essa última modalidade é raramente utilizada pelas empresas, pois há um risco de o devedor principal do título de credito (cheque, nota promissória, duplicata, entre outros) tornar-se inadimplente em relação ao pagamento do respectivo título, e não haver a integralização do capital social subscrito, podendo a atividade empresária não alcançar os fins a que se propôs. Além disso, o endossante- que é o sócio- responde pela solvência do devedor nos termos do Art 1.005 do Código Civil, senão vejamos: “o sócio que, a título de quota social, transmitir domínio, posse ou uso, responde pela evicção; e pela solvência do devedor, aquele que transferir crédito."

Destacamos ainda que o capital social não poder ser integralizado por sócio de sociedade empresária por meio de prestação de serviços, exceto na sociedade simples. ${ }^{7} \mathrm{~A}$ vedação encontra guarida nos termos do já citado Art. 1.055, § $2^{\circ}$ do Código Civil. Já quando a integralização do capital social se der por meio da transferência de domínio -propriedadeposse ou apenas o uso do bem, responderá aquele que transferiu o bem para integralizar capital social por eventual evicção, também nos termos do mencionado Art. 1.005 do Código Civil.

Além disso, importante mencionar que quando há a transferência da propriedade, o bem deixa de ser do sócio e passa a ser da sociedade ou da EIRELI, havendo alteração na propriedade do respectivo bem, inclusive junto ao órgão competente de seu registro (exemplo Detran, Registro de Imóveis, etc)

Quando o capital social é integralizado por meio de bens, os sócios da sociedade assumem importante responsabilidade em relação a avaliação desses bens, de acordo com a observância do Art. 1.055, § $1^{\circ}$ do Código Civil, "pela exata estimação de bens conferidos ao

\footnotetext{
${ }^{7}$ A sociedade simples é de natureza não empresarial, ou seja, é utilizada para formalizar sociedades cujo objeto decorram de atividades cientificas, artísticas, intelectuais ou literárias, nos ternos do parágrafo único do Art 966 do Código Civil, como por exemplo, sociedade de advogados, arquitetos, médicos, etc. Nesses casos, em que o sócio de sociedade simples integraliza capital social por meio de serviços, aplica-se as regras do Art. 1.006 do Código Civil, que prevê o seguinte: "o sócio, cuja contribuição consista em serviços, não pode, salvo convenção em contrário, empregar-se em atividade estranha à sociedade, sob pena de ser privado de seus lucros e dela excluído." E além disso, prevê a legislação, que nesse caso, de o sócio de sociedade simples integralizar o capital social por meio de serviços, não participará de eventual chamada de capital para recapitalizar a sociedade, apenas participa dos lucros na proporção da média das quotas, nos termos do Art. 1.007 da mesma codificação anteriormente mencionada, senão vejamos: "salvo estipulação em contrário, o sócio participa dos lucros e das perdas, na proporção das respectivas quotas, mas aquele, cuja contribuição consiste em serviços, somente participa dos lucros na proporção da média do valor das quotas".
} 
capital social respondem solidariamente todos os sócios, até o prazo de cinco anos da data do registro da sociedade". Tal dispositivo, assegura a realidade do valor atribuído ao bem utilizado para integralizar o capital social, impondo, responsabilidade solidária pelo prazo de 5(cinco) anos, contados do registro da empresa, entre os sócios e do titular da EIRELI.

E é no cenário de capitalização, com alteração do capital social no curso da empresa e integralização por meio de bem, entendemos que a exata estimação do valor conferido aos bens utilizados para a integralização do capital social também confere responsabilidade solidária pelo prazo de 5 (cinco) anos, a contar da data de nova capitalização averbada no Cartório de Registro de empresas mercantis, a cargo das juntas comerciais, nos termos da Lei $\mathrm{n}^{\circ} 8.934 / 1994$. E, portanto, a realidade do valor atribuído a título de capital social não deve ser retórica ou mera estimativa, conforme afirma Mamede (2013), e nem sequer superavaliados.

A consequência de não atribuir valor real aos bens utilizados para integralizar capital social possui consequências jurídicas. Em relação a EIRELI e a sociedade limitada unipessoal ou pluripessoal, perderá a segurança jurídica proporcionada pela constituição de pessoa jurídica, e havendo prova judiciais de credores em relação a fraude do valor atribuído ao bem usado para integralizar capital social, será possível buscar eventual pagamento a ser realizado à credores no patrimônio pessoal dos sócios, único sócio ou titular da EIRELI, após exaurido todo o patrimônio social.

Em relação a sociedade limitada pluripessoal há importante consequência jurídica quando o capital social declarado no ato constitutivo, que é o contrato social, não for totalmente integralizado pelos sócios à sociedade. Nos termos do Art 1.052 do Código Civil : "na sociedade limitada, a responsabilidade de cada sócio é restrita ao valor de suas quotas, mas todos respondem solidariamente pela integralização do capital social."

Situações em que o valor do capital social é lançado em valores elevados no ato constitutivo para que a empresa possa atender requisito para fins de financiamento, busca de investidor, participação de editais de licitação, editais de fomento ou outras situações, em que o valor do capital social declarado se torna importante item para a participação da empresa no pleito, podem se tornar uma armadilha para todos os sócios, visto que se um dos sócios não integralizar todo o capital social subscrito, poderá eventual credor buscar o pagamento do seu credito no patrimônio pessoal de qualquer sócios, diante da solidariedade existente entre os sócios da sociedade nesses casos, afastando a segurança jurídica da autonomia patrimonial da pessoa jurídica. 
Para Mamede (2013), o princípio da publicidade também norteia o capital social. O ato constitutivo e suas alterações devem ser registrados no órgão competente, e assim como as demais informações constantes no ato constitutivo (nome do titular, sócios, distribuição de quotas em sociedade limitada, endereço, profissão, e demais informações obrigatórias) são públicas a terceiros. De acordo com o Art. 29 da Lei no 8.934/1994 "qualquer pessoa, sem necessidade de provar interesse, poderá consultar os assentamentos existentes nas juntas comerciais e obter certidões, mediante pagamento do preço devido".

Diante disso, conforme Bertoldi, Ribeiro $(2013)^{8}$, a ideia de que o capital social é a garantia mínima dos credores, permite, em tese, em ao realizar negócios importantes e/ou de altos montantes com determinada empresa é possível consultar o seu capital social, a fim de minimizar riscos de inadimplência. E é justamente nesse intuito que o Art. 1.082 do Código Civil, se reporta a sociedade limitada, cujas mesmas regras são utilizadas pela EIRELI ${ }^{9}$ prevê que "Pode a sociedade reduzir o capital, mediante a correspondente modificação do contrato: I - depois de integralizado, se houver perdas irreparáveis; II - se excessivo em relação ao objeto da sociedade”. Apesar de a legislação estabelecer uma faculdade, é fortemente recomendado que haja alteração do capital para, nesses casos, diminui-lo, a fim de não gerar argumento que possa ser usado contra a própria pessoa jurídica, visto ser possível que o capital social esteja acima do patrimônio real da pessoa jurídica.

Além disso, em relação a diminuição do capital social, importante ainda observar que “a redução do capital será realizada com a diminuição proporcional do valor nominal das quotas, tornando-se efetiva a partir da averbação, no Registro Público de Empresas Mercantis, da ata da assembleia que a tenha aprovado".(Art 1.083 do CC)

De acordo com Mamede (2013, p. 83) “o capital social deve apresentar-se estável, constante, fixo. Não é passível de variabilidade constante, o que traria insegurança. Mas não é imutável; desde que respeitados procedimentos previstos em lei”, o capital pode ser aumentado (capitalizado) ou reduzido (descapitalizado), conforme autorização expressa nos

\footnotetext{
${ }^{8}$ Importante mencionar que há controvérsias em relação a máxima de que o capital social é a garantia mínima dos credores, visto que na prática é possível integralizar o capital social com bens de difícil comercialização ou arrematação em hasta publica, quando penhorados.

${ }^{9}$ Dispõe o Art. 980-A do Código Civil: A empresa individual de responsabilidade limitada será constituída por uma única pessoa titular da totalidade do capital social, devidamente integralizado, que não será inferior a 100 (cem) vezes o maior salário-mínimo vigente no País. [...] $\S 6^{\circ}$ Aplicam-se à empresa individual de responsabilidade limitada, no que couber, as regras previstas para as sociedades limitadas.
} 
Art. 1.081 e 1.082 do Código Civil para aumento e diminuição do capital social, respectivamente.

Nas sociedades limitadas e na EIRELI- que utiliza as mesmas regras da sociedade Limitada, conforme Art 980-A do CC-, o capital pode ser aumentado desde que todo o capital social já tenha sido integralizado pelos sócios. Além disso, nos termos do Art 1.081 do CC "até trinta dias após a deliberação, terão os sócios preferência para participar do aumento, na proporção das quotas de que sejam titulares" passado esse período, a sociedade poderá ofertar para terceiros, exceto se o ato constitutivo tratar de forma diferente a questão. Tal aumento de capital social poderá ocorrer mediante o ingresso de novos fundos na sociedade, mediante subscrição de novas quotas ou então a incorporação dos lucros sociais acumulados ao capital social, situação em que os sócios deliberam, em reunião ou assembleia, por abrir mão de suas respectivas participações nos lucros, revertendo-os em proveito da sociedade. (BERTOLDI, RIBEIRO, 2015) ${ }^{10}$.

\section{Procedimentos adotados pelos sócios na falta de integralização do capital social}

Uma das principais obrigações dos sócios, senão a principal, é integralizar o capital social subscrito pelo sócio ou pelo único titular da empresa, no ato constitutivo. Àquele que não o faz torna-se sócio remisso ou titular remisso em relação a pessoa jurídica.

Nessa linha, há um conjunto normativo que estabelece o procedimento a ser utilizado quando não houver a integralização do capital social subscrito no ato constitutivo. Em se tratando de sociedade podemos verificar, que o art. Art. 1.004 do CC, em que pese estar previsto no capítulo que trata da sociedade simples, pode, em face do Art 1.053 do mesmo diploma legal ser utilizado para a sociedade limitada, prevendo o seguinte:

Art. 1.004. Os sócios são obrigados, na forma e prazo previstos, às contribuições estabelecidas no contrato social, e aquele que deixar de fazê-lo, nos trinta dias seguintes ao da notificação pela sociedade, responderá perante esta pelo dano emergente da mora.

\footnotetext{
${ }^{10}$ Nas sociedades anônimas, o aumento do capital social, segue o regramento da Lei 6.404/1976 e o estatuto social da sociedade, especialmente a previsão do Art 166 da Lei das Sociedades Anônimas - LSA.
} 
Parágrafo único. Verificada a mora, poderá a maioria dos demais sócios preferir, à indenização, a exclusão do sócio remisso, ou reduzir-lhe a quota ao montante já realizado, aplicando-se, em ambos os casos, o disposto no $§ 1^{\circ}$ do Art. 1.031.

Portanto, a primeira medida a ser tomada pela sociedade e demais sócios é notificar o sócio remisso, para que pague em trinta dias o valor ou transferir o bem, de acordo com o ato constitutivo.

Importante nesse caso a observação de duas questões: a primeira questão relevante diz respeito ao contrato social, que deve especificar exatamente como será integralizado o capital social por cada um dos sócios, ou seja, caso houver concessão de prazo para a integralização do capital social, deve o contrato social mencionar a data certa ou o prazo com a previsão do início da sua contagem. A segunda questão é em relação a notificação propriamente dita, a partir do parâmetro previsto no contrato, que será a prova de que o sócio encontra-se em débito com a sociedade, é fundamental que haja a notificação.

Tal notificação pode ser realizada por meio de ação judicial de notificação, em que a sociedade terá que contratar profissional com jus postulandi, que por meio de procuração com poderes específicos, irá promover a ação, além disso, haverá pagamento de custas processuais- exceto em caso de concessão de justiça gratuita- e honorários advocatícios. Ou então, poderá a notificação ser realizada extrajudicialmente, por meio de notificação ao devedor pelo Cartório respectivo, com fé pública, nesse caso haverá o custo dos emolumentos.

A notificação ao sócio devedor muitas vezes encontra resistências entre os demais sócios, visto que não raras as vezes a sociedade é calcada em valores como amizade, companheirismo, afetos, relações familiares, etc. No entanto, o procedimento é fundamental para a solução da situação com segurança jurídica.

Após notificada, caso a parte devedora não efetue o pagamento em trinta dias, o devedor estará em mora, e, portanto, evidenciada a quebra a figura do affectio societatis entre os sócios, que nada mais é do que a lealdade e confiança entre os sócios e o comprometimento com a pessoa jurídica constituída, o que poderá acarretar na exclusão do sócio da sociedade. Conforme o art. Art. 1.058 do CC, que prevê o seguinte:

Não integralizada a quota de sócio remisso, os outros sócios podem, sem prejuízo do disposto no Art. 1.004 e seu parágrafo único, tomá-la para si ou transferi-la a terceiros, excluindo o primitivo titular e devolvendo-lhe o que houver pago, deduzidos os juros da mora, as prestações estabelecidas no contrato mais as despesas. 
Se a opção for pela exclusão do sócio remisso, após a notificação e a constituição do mesmo em mora, é possível faze-lo de duas formas, judicial ou extrajudicial. No primeiro caso nos termos dos Arts. 1.030 e $1.031^{11}$ do CC, podendo ocorrer em sede de ação e dissolução parcial de sociedade com fundamento nos Art 599 e seguintes do Código de Processo Civil de 2015, na segunda pelo procedimento administrativo, estabelecido no Art 1.085 do CC, se presentes os pressupostos legais ${ }^{12}$.

Dessa forma, o capital social é um importante elemento na constituição de empresas, e especialmente daquelas que constituem pessoa jurídica, gerando vários efeitos jurídicos em relação aos sócios e terceiros.

Por fim, como visto, em que pese, não haver imposição legal da comprovação da integralização do capital social no ato do registro da empresa na junta comercial, por meio de recibo, transferência bancário ou documento que prove a transferência de bem para a pessoa jurídica. Desta forma, sendo suficiente a declaração da transferência de valores, no ato constitutivo, com o registro contábil da operação, trata-se de medida preventiva e garantia de segurança jurídica a sua efetiva realização.

\section{Considerações finais}

Capital social na ocasião da abertura de uma empresa são os recursos que os sócios investem sem uma garantia de retorno. Este valor irá constar em no ato constitutivo da

11 Art. 1.030. Ressalvado o disposto no Art. 1.004 e seu parágrafo único, pode o sócio ser excluído judicialmente, mediante iniciativa da maioria dos demais sócios, por falta grave no cumprimento de suas obrigações, ou, ainda, por incapacidade superveniente. Parágrafo único. Será de pleno direito excluído da sociedade o sócio declarado falido, ou aquele cuja quota tenha sido liquidada nos termos do parágrafo único do Art. 1.026.

Art. 1.031. Nos casos em que a sociedade se resolver em relação a um sócio, o valor da sua quota, considerada pelo montante efetivamente realizado, liquidar-se-á, salvo disposição contratual em contrário, com base na situação patrimonial da sociedade, à data da resolução, verificada em balanço especialmente levantado. $1 \stackrel{\circ}{\circ} \mathrm{O}$ capital social sofrerá a correspondente redução, salvo se os demais sócios suprirem o valor da quota. $\S 2 \stackrel{\circ}{\circ}$ quota liquidada será paga em dinheiro, no prazo de noventa dias, a partir da liquidação, salvo acordo, ou estipulação contratual em contrário.

12 Art. 1.085. Ressalvado o disposto no Art. 1.030, quando a maioria dos sócios, representativa de mais da metade do capital social, entender que um ou mais sócios estão pondo em risco a continuidade da empresa, em virtude de atos de inegável gravidade, poderá excluí-los da sociedade, mediante alteração do contrato social, desde que prevista neste a exclusão por justa causa. Parágrafo único. Ressalvado o caso em que haja apenas dois sócios na sociedade, a exclusão de um sócio somente poderá ser determinada em reunião ou assembleia especialmente convocada para esse fim, ciente o acusado em tempo hábil para permitir seu comparecimento e o exercício do direito de defesa. 
empresa e também em uma conta do Balanço Patrimonial. Não existe nenhuma fórmula ou padrão para a definição do capital social para a abertura de uma empresa.

Em que pese as consequenciais jurídicas possuem maior impacto junto aos tipos empresariais que constituem pessoa jurídica, como a EIRELI e a Sociedade Limitada, que quando constituídas promovem autonomia patrimonial por parte da pessoa jurídica, os tipos empresariais que não constituem pessoa jurídica para fins legais, como o MEI e a figura do Empresário Individual, também se beneficiam da correta indicação do capital social.

O plano de negócios é um excelente instrumento de planejamento para estimar um aporte de recursos capaz de sustentar o financiamento de suas operações enquanto a empresa não consiga ter resultados financeiros decorrentes da atividade econômica. A fixação do valor do capital social a partir de um planejamento, por meio de um plano de negócio, garante maior credibilidade da empresa junto a investidores, parceiros, novos sócios, colocação no mercado e manutenção do negócio com saúde financeira, favorecendo o crescimento e com condições reais de pagamento das obrigações contraídas, evitando fechamento precoce.

O Estado brasileiro estabeleceu, para a EIRELI, valor mínimo de capital social, já os demais tipos empresariais individuais e a sociedade limitada não possuem capital social mínimo a ser constituído, no entanto, importante que o valor seja apurado no planejamento já mencionado e efetivamente integralizado pelos sócios, não se consumando como mera retórica e capital ficto. Apurou-se também que patrimônio social e o capital social são diferentes, e o último, embora mais estável, pode sempre ser alterado, principalmente nos casos estabelecidos nos termos dos Art. 1.081 e 1.082 do Código Civil, a fim de maior proteção jurídica.

A integralização do capital social é a principal obrigação do único titular da empresa e dos sócios de sociedade limitada. A máxima de que o capital social é a garantia mínima dos credores, permite que o credor possa indicar bens pessoais do titular da EIRELI e de qualquer sócio da sociedade Limitada (mesmo daqueles que integralizaram capital social subscrito), sempre que seu credito não é pago e o capital social não estiver integralizado, mitigando a segurança jurídica decorrente do tipo empresarial adotado.

Bem como, a integralização do capital social por meio da transferência de bens também deve ser conduzida com seriedade, visto que, em caso de sociedade, todos os sócios são responsáveis pelo valor atribuído ao bem utilizado na integralização do capital social. 
Assim como, o titular da EIRELI, durante o prazo de 5 (cinco) anos ou da data de nova capitalização por meio de bens transferidos para a sociedade ou EIRELI.

Por fim, observa-se, que a questão da integralização do capital social é tutelada pelo Estado, estabelecendo, inclusive, procedimento a ser aplicado pelos demais sócios na falta do cumprimento da obrigação por algum sócio, como pode ser observado no Art 1.058 do CC.

\section{Referências}

ASSAF NETO, Alexandre. Finanças corporativas e valor. São Paulo: Atlas, 2010.

BAGGIO, Adelar Francisco. BAGGIO, Daniel Knebel. Empreendedorismo: Conceitos e Definições. IMED. Rev. de Empreendedorismo, Inovação e Tecnologia, 1(1): 25-38, 2014 ISSN 2359-3539. Disponível em: 〈file:///C:/Users/Usuario/Downloads/612-2762-2-PB.pdf〉. Acesso em: nov/2020

BERTOLDI, Marcelo M.; RIBEIRO, Marcia Carla Pereira. Curso avançado de direito comercial. 8. ed. reform. atual. e ampl. São Paulo: RT, 2013.

BORGES, Cândido. O papel do capital social do empreendedor na criação de empresas tecnológicas - RAI - Revista de Administração e Inovação, São Paulo, v. 8, n. 2, p.162-181, jul ./set. 2011. Disponível em: <http://www.revistas.usp.br/rai/article/view/79231>. Acesso em: ago/2020.

BOURDIEU, Pierre. Le capital social: notes provisoires, Tradução: Miguel Serras Pereira Actes Rech. Sci. Soc..1980.

Esboço de uma teoria da prática - Precedido de Três Estudos de Etnologia . Tradução: Miguel S. Pereira. Cabila Capa comum - janeiro, 2002.

BRASIL. Lei n ${ }^{\circ}$ 10.406, de 10 de janeiro de 2002. Institui o Código Civil.

BRASIL. Lei $n^{\circ} 8.934$ de 18 de novembro de 1994 Dispõe sobre o Registro Público de Empresas Mercantis e Atividades Afins e dá outras providenciais.

BRASIL. Lei $\mathrm{n}^{\mathrm{o}} 11.638$, de 28 de dezembro de 2007. Altera e revoga dispositivos da Lei $\mathrm{n}^{\circ}$ 6.404, de 15 de dezembro de 1976, e da Lei $\mathrm{n}^{\circ}$ 6.385, de 7 de dezembro de 1976, e estende às sociedades de grande porte disposições relativas à elaboração e divulgação de demonstrações financeiras. Disponível em:

<http://www.planalto.gov.br/ccivil_03/_Ato2007-2010/2007/Lei/L11638.htm>. Acesso em: nov/2020. 
BRASIL. Lei $\mathrm{n}^{\circ}$ 13.874, de 20 de setembro de 2019. Institui a Declaração de Direitos de Liberdade Econômica; estabelece garantias de livre mercado; altera as Leis nos 10.406 , de 10 de janeiro de 2002 (Código Civil), 6.404, de 15 de dezembro de 1976, 11.598, de 3 de dezembro de 2007, 12.682, de 9 de julho de 2012, 6.015, de 31 de dezembro de 1973, 10.522, de 19 de julho de 2002, 8.934, de 18 de novembro 1994, o Decreto-Lei $n^{\circ}$ 9.760, de 5 de setembro de 1946 e a Consolidação das Leis do Trabalho, aprovada pelo Decreto-Lei ${ }^{\circ}$ 5.452, de $1^{\circ}$ de maio de 1943; revoga a Lei Delegada $\mathrm{n}^{\circ}$ 4, de 26 de setembro de 1962, a Lei $\mathrm{n}^{\mathrm{o}}$ 11.887, de 24 de dezembro de 2008, e dispositivos do Decreto-Lei $\mathrm{n}^{\circ} 73$, de 21 de novembro de 1966; e dá outras providências

BRASIL. Mapa de Empresas. Disponível em https://www.gov.br/governodigital/pt-br/mapade-empresas/boletins/mapa-de-empresas-boletim-do-3o-quadrimestre-de-2020.pdf Acessado em 03 de fev/2021.

CACIATORI JR, I.; IAROZINSKI NETO, A. Classificação das principais dificuldades enfrentadas pelas pequenas e empresas (PMEs). In: SIMPOSIO DE ENGENHARIA DE PRODUÇÃO, 13., 2006, Bauru. Anais [...]. Bauru: UNESP, 2006.

CHAGAS, Edilson Enedino das. Direito Empresarial esquematizado. $6^{\text {a }}$ edição. São Paulo: Saraiva, 2019.

DORNELAS, José Carlos Assis. Empreendedorismo ideias em negócios. 3 ed. Rio de janeiro: Elsevier, 2008.

GITMAN, Lawrence J. Princípios de administração financeira. 12. ed. São Paulo: Pearson, 2010.

MAMEDE, Gladston: Manual do direito empresarial. 7.ed. São Paulo: Atlas, 2013.

PUTNAM, Robert (1996). Comunidade e Democracia. A Experiência da Itália Moderna. Rio de Janeiro: Fundação Getúlio Vargas, tradução de Making Democracy Work: Civic Traditions in Modern Italy (1993).

SANTOS, Edno Oliveira dos. Administração financeira da pequena e média empresa. 2 ed. São Paulo: Atlas, 2010.

SEBRAE - Serviço Brasileiro de Apoio as Micros e Pequenas empresas. Capital social: saiba como aplicá-lo em sua empresa (2020). Disponível em: $<$ https://www.sebrae.com.br/sites/PortalSebrae/ufs/ap/artigos/como-definir-o-capital-socialde-uma-empresa,>. Acesso: ago/2020. 
Sobrevivência das empresas (2020). Disponível em: <https://datasebrae.com.br/sobrevivencia-das-empresas/ >. Acesso: nov/2020. 